Original Research Paper

\title{
Variations in Pathogenicity and Molecular Characterization of Infectious Bursal Disease Virus (IBDV) In Egypt
}

\author{
${ }^{1}$ Mahmoud E. Sedeik, ${ }^{1}$ Ashraf M. Awad, ${ }^{1}$ Heba Rashed and ${ }^{2}$ Wael K. Elfeil \\ ${ }^{I}$ Department of Poultry and Fish Diseases, Faculty of Veterinary Medicine, Alexandria University, Egypt \\ ${ }^{2}$ Avian and Rabbit Medicine department, Faculty of Veterinary Medicine, Suez Canal University, Ismailia, Egypt
}

Article history

Received: 14-03-2018

Revised: 12-04-2018

Accepted: 15-05-2018

Corresponding Author:

Mahmoud E. Sedeik

Department of Poultry and Fish

Diseases, Faculty of Veterinary

Medicine, Alexandria

University, Egypt

Email: dr.mahmoud.seddik@gmail.com

\begin{abstract}
Infectious bursal disease consider a vital threat to poultry industry worldwide and It has special potentiality in Egypt as the country become endemic with several clades from avian influenza from both types highly pathogenic (H5N1 and H5N8) and low pathogenic one (H9N2). The Egyptian government depends on the inactivated vaccine strategy to control avian influenza and any infection with IBD in broiler flocks alter the inactivated vaccine response in addition to other economic loss from the IBD infections. The present study was conducted to investigate the variations in pathogenicity and molecular characterization of IBDV in Egypt. Twenty-six bursal samples were collected from different chicken farms during the period of June 2015 to April 2016; the virus was isolated by inoculation of bursal suspension into 10-11 days ECE via CAM. Reverse Transcriptase Polymerase Chain Reaction (RT-PCR) was applied for IBD targeting Hypervariable Region (HVR) of VP2 gene. Out of 26 tested isolates, 11 isolates were positive by RT-PCR. Sequence analysis of PCR products of 11 positive isolates were carried out and revealed that all +ve isolates were characterized as very virulent (vvIBDV) strains and they showed 80.6-97.5\% identity with Giza 2008 IBD strain. Six selected positive vvIBDV isolates were used to study the pathogenicity of IBDV in 105 one-day-old SPF chickens. At day 211st the SPF chickens were divided into 7 groups $15 \mathrm{bird} / \mathrm{each}$, the groups 1-6 were experimentally infected with $0.1 \mathrm{~mL}$ of EID50 of 6 selected positive IBDV field isolates via nasoocular route. Group 7 kept as non-infected control. Experimental infection caused clinical signs and gross lesions typical for IBDV and mortalities ranged from 26.7 to $80 \%$ as well as bursal/body weight index lower than 0.7 indicating bursal atrophy. The Microscopical examination of bursal samples collected at days 3 and 7 post-infection revealed different degrees of histopathological bursal changes as lymphoid depletion with proliferating interfollicular connective tissue, atrophy of the follicles, stromal edema and associated with inflammatory response. The circulating strains were highly related to vvIBDV strains belonging to serotype-1 isolates and indicating that they are highly pathogenic to 21-day-old SPF chickens and that vvIBDV strains succeeded in surviving in the Egyptian farms despite of the application of intensive vaccination programs.
\end{abstract}

Keywords: IBDV, VP2 Gene, Bursa, Variant Strain, vvIBDV

\section{Introduction}

The Infectious Bursal Disease Virus (IBD/IBDV) or Gumboro Disease is an acute highly contagious viral disease of young chickens characterized by a hemorrhagic syndrome, severe damage in cloacal bursa, immunosuppression and high mortality generally at 3 to 6 weeks of age (Eterradossi and Saif, 2013). IBD was first reported in 1957 in Southern Delaware town of Gumboro, U.S.A (Cosgrove, 1962; Parkhurst, 1964). It 
is one of the most economical important diseases that affects commercially produced chickens worldwide (Müller et al., 2003). IBDV is classified as a member of the family Birnaviridae and genus Avibirnaviridae. Its genome consists of 2 segments of double-stranded RNA (dsRNA) and characterized by non-enveloped icosahedral capsid (Leong et al., 2000). Two serotypes of the virus have been described; Serotype1 IBDV strains, pathogenic to chickens (Van den Berg et al., 2004), whereas serotype 2 strains are non-pathogenic (McFerran et al., 1980). In Egypt, El-Sergany et al. (1974) diagnosed the IBD for the first time on the basis of its specific pathological lesions. Very virulent IBDV were reported since its first introduction in 1989 in vaccinated Egyptian flocks by ElBatrawi (1990). RT-PCR has been useful in detecting IBDV serotypes and to a lesser extent, differentiating IBDV subtypes. Amplifying the VP2 hypervariable region, in combination with DNA sequencing of the PCR product, can differentiate classic, variant and vvIBDV strains because variant and vvIBDV have characteristic nucleotide and amino acid substitutions. This approach is a valuable tool for molecular epidemiological studies on IBDV (Islam et al., 2012). The Hyper Variable Region (HVR) on VP2 (206-350 Amino Acid) contains the most informative genetic data regarding strain variability, it was chosen for sequence analysis to characterize IBDV strains molecularly, allowing analysis of variations that happen naturally or by attenuation in different strains, leading to changes in antigenicity and/or virulence (Jackwood et al., 2008). The IBD infection consider one of the immunosuppressive disease which can be predisposing factor for other bacterial or viral pathogen or failure in inactivated vaccine application, $E$. coli infection can associated with the IBD infection and cause economic losses in poultry flocks (Eid et al., 2016). Immunosuppression effect can alter the immune modulator specially pathogen recognition receptor pathways which intern can affect the general immune response to different pathogens (Abouelmaatti et al., 2013; Elfeil et al., 2012; 2016). The pathogenicity of IBDV isolates was evaluated by experimental infection of susceptible chickens based on clinical signs, mortality, gross lesions, Bursa: Body weight index and histopathological analysis of the bursa of Fabricius (Jackwood et al., 2011). This study aims to investigate the variations in pathogenicity and molecular characterization of IBDV in Egypt.

\section{Materials and Methods}

\section{Field Samples}

A total number of 26 chicken farms were investigated for IBD outbreak over the period of 2015-2016. Bursal samples were collected and processed to prepare a bursal homogenate. About $10 \%$ tissue suspensions were prepared as described by Hirai and Shimakura (1974).

\section{Virus Isolation}

The tissue suspensions were used for virus isolation by inoculation in 9-11 days embryonated chicken eggs via CAM. The allantoic fluids were collected for applying rapid slide haemagglutination test as reported by Wlliams (2016).

\section{Molecular Identification by RT-PCR}

RNAs were extracted from pools of CAM and embryo cell extract of 26 field isolates using QIAamp Viral RNA Mini Kit (Qiagen, Valencia, USA). Cat. No.52904. the procedure was performed according to the company's instruction. A set of primers were used: Forward primer: [AUS GU: 50-TCA CCG TCC TCA GCTTAC CCA CAT C-30]. Reverse primer: [AUS GL: 50-GGA TTT GGG ATC AGCTCG AAG TTG C-30] (Metwally et al., 2009).

\section{Sequence Analysis of HVR of VP2 Gene}

Gel containing DNA band of the expected size $(620$ bp) was excised and purified with the QIA quick Gel Extraction Kit (Qiagen) according to the manufacturer instruction. The purified PCR products were sequenced directly using big dye Terminator V3.1 cycle sequencing kit (Perkin-Elmer, Foster city, CA, USA). The phylogram was drawn using also MEGA 5 software. The alignment of the viruses in the study was done using DNA starMegAlign software. Egyptian viruses and other international reference strains from the Genbank and were available from the National Center for Biotechnology Information (NCBI) infectious bursal disease viruses' resource (http://www.ncbi). Finally, the identity percent and divergence between all viruses was carried out.

\section{Determination of EID50 of 6-Selected IBDV Field Isolates}

Titration of selected IBDV field isolates no. (21, 22, 23, 24, 25 and 26) was carried out and the EID50 was calculated according to Reed and Muench (1938).

\section{Pathogenicity Experiment}

Hundred and five SPF chicks were reared in previously fumigated house, provided with food and water ad libitum. This study was carried out in strict accordance with the recommendations of the Committee on the Ethics of Animal Experiments of Alexandria University, Egypt. All procedures and experiments complied with the guidelines and were approved by the Local Ethic Commission of the Animal Experiments of Alexandria University with respect to animal experimentation and care of animals under study. All efforts were made to minimize suffering. At 21st day-old, the chickens were divided into 7 groups, each contain 15 birds and housed separately in strictly isolated disinfected rooms. The chickens were experimentally infected (Groups 1-6 were infected with 6-selected IBDV positive field isolates nasoocular with $0.1 \mathrm{~mL}$ of EID50 but Group-7 kept as noninfected control group)as shown in Table 1. 
Table 1: Experimental design of SPF chickens experimentally infected with Selected 6 IBDV field isolates

\begin{tabular}{lllll}
\hline Group no. & No. of birds & Isolate no. & age of infection & dose of infection \\
\hline G1 & 15 & Field isolate no.21 & 21 day & $0.1 \mathrm{~mL}$ of EID50 \\
G2 & 15 & Field isolate no.22 & 21 day & 0.1 mL of EID50 \\
G3 & 15 & Field isolate no.23 & 21 day & 0.1 mL of EID50 \\
G4 & 15 & Field isolate no.24 & 21 day & 0.1 mL of EID50 \\
G5 & 15 & Field isolate no.25 & 21 day & $0.1 \mathrm{~mL}$ of EID50 \\
G6 & 15 & Field isolate no.26 & 21 day & $0.1 \mathrm{~mL}$ of EID50 \\
G7 (control $-\mathrm{ve})$ & 15 & Non infected & Non infected & Non infected \\
\hline
\end{tabular}

G: Group No: Number -ve: Negative $\mathrm{EID}_{50}=$ embryo infective dose 50

Table 2: EID50 of six-selected IBD field isolates

\begin{tabular}{lllll}
\hline Field isolate no. & No of eggs/dilution & & & \\
\hline 21 & $(10-1-10-7)$ & Route of inoculation & Dose/ml & Titer (EID50) \\
22 & 4 & CAM & 0.1 & $10-4.5$ \\
23 & 4 & CAM & 0.1 & $10-3.6$ \\
24 & 4 & CAM & 0.1 & $10-3.5$ \\
25 & 4 & CAM & 0.1 & $10-4.6$ \\
26 & 4 & CAM & 0.1 & $10-4.8$ \\
\hline
\end{tabular}

EID50: Embryo Infective Dose 50. CAM: Chorioallantoic Membrane

All groups kept under daily observation for 10 days post infection and clinical signs, mortality rate, PM lesions; body and bursal weight were recorded.

\section{Calculation of Bursal Body Weight Index}

Bursal body weight ratio and $\mathrm{BB}$ index were calculated according to the formulas of Lucio and Hitchner (1979):

$$
\begin{gathered}
\text { Bursa / body weight ratio } \\
=\frac{\text { weight of bursa in grams }}{\text { Bird's body weight in grams }} \times 1000 \\
B / \text { B weight index } \\
=\frac{\text { Bursa / body weight ratio of infected birds }}{\text { Bursa / body weight ratio of control birds }}
\end{gathered}
$$

Chickens with BB index lower than 0.7 were considered to have bursal atrophy (Lucio and Hitchner, 1979).

\section{Calculation of EID50 of 6-Selected Field Isolates}

The egg-infected dose 50 calculated for six-selected infectious Bursal Disease virus (IBD) as shown in Table 2.

\section{Histopathological Examination}

Five Bursae from freshly dead or sacrificed birds collected at 3th and 7th day post infection from each group, Tissue specimen fixed in 10\% neutral buffered formalin solution for at least $24 \mathrm{~h}$. The fixed specimens were processed through the conventional paraffin embedding technique (Culling, 1974). Paraffin sections of $5 \mu \mathrm{m}$ thickness were prepared and stained with (H\& E stain) then examined under optical microscope.

\section{Results}

\section{IBDV Isolation in Embryonated Chicken Eggs (ECE)}

Mortality patterns of infected embryos were varied between $0-100 \%$, Rapid slide HA test proved that the allantoic fluids of all field isolates were negative for hemagglutininating agents. Embryos which died from 37 days post inoculation showed some gross pathological lesions as abdominal and/or cerebral edema, dwarfing, cutaneous congestion and hemorrhages particularly along feather tracts, in cerebral region and toe joints, mottled-appearing necrosis and congestion of liver sometimes with a greenish discoloration, congested kidney, pale heart and enlarged spleen and Sometimes CAM had hemorrhagic areas.

\section{Molecular Characterization of IBDV Field Isolates: Reverse Transcriptase-Polymerase Chain Reaction (One-Step RT-PCR)}

There were 11 out of 26 field isolates were positive RT-PCR with a percent of $42.3 \%$ (5 out of 12 in ElBehera; 3 out of 7 in Kafr El-sheikh; 1 in Marsa Matrouh and 2 out of 6 in Alexandria with a percent of $41.6 \%$; $42.8 \% ; 100 \%$ and $33.3 \%$ respectively). Eleven RT-PCR positive isolates were detected in 2 layers farms (40\%), 4 native baladi farms $(57.1 \%)$ and 5 broilers farms $(35.7 \%)$ as shown in Table 3 and Fig. 1.

\section{Sequencing and Phylogenic Analysis}

Sequence analysis of HVR of VP2 of 11 IBDV isolates was conducted and revealed that all isolates were highly genetically related and have amino acid identity between each other (73.8-100\%), between Egyptian vvIBDV (Giza 2008) strains (80.6-97.5\%) but when compared with classical vaccinal strains it showed (74.4-95.6\%) identity as 
shown in Fig. 2. From the phylogenetic tree, it was found that all isolates were clustered together and closely related to previous isolated vvIBDV strains from Egypt (Fig. 2). From the phylogenetic tree, it was found that all isolates were clustered together and closely related to previous isolated vvIBDV strains from Egypt (Fig. 3).

\section{Determination the Pathogenicity of 6-Selected IBDV Field Isolates}

All chickens were observed for 10 days post infection, clinical signs, mortality rates, gross lesions, body weight, bursal weight, bursal body weight ratio and bursal body weight index were recorded.

\section{Clinical Signs, Mortality and Gross Lesions Post Infection}

Groups (1-6) induced 80-100\% morbidity; clinical signs appeared suddenly at 2 nd day post-infection in form of depression, anorexia, ruffled feathers, huddling, tremors, prostration, whitish watery diarrhea and soiled vent. Groups (2, 3, 4 and 5) showed more severe clinical signs than other groups. Mortality started from third to $6^{\text {th }}$ days post-infection (26.7-80\%). The highest mortality rates were appeared in groups $2,3,4,5$ with percentage of $60 \%, 80 \%, 46.7 \%$ and $40 \%$ receptively. The lowest mortality rate appeared on groups (1 and 6) with percentage of $33.5 \%$ and $26.7 \%$ receptively. The control negative Group (7) appeared normal throughout observation period. The pattern of mortality during observation period is presented in Table 4. The lesions included dehydration, difficult separation of skin on abdominal muscle, congestion and hemorrhages on thigh (groups 1, 3, 4 and 5) and abdominal muscles (groups 4 and 5); hemorrhage at junction between proventriculus and gizzard (Groups 2, 3, 4 and 5); infarcted and darken discolored liver; swollen kidney with petechial hemorrhage and ureters filled with urates. The bursa of Fabricius was enlarged, edematous with gelatinous yellow transudate covering serosal surface at $3^{\text {rd }} / 4^{\text {th }}$ days post infection, sometimes hemorrhagic, or atrophied in most dead or sacrificed birds at 7 th day post infection. Spleen appeared enlarged or congested in some cases. Bursa/body weight ratio and bursa/body weight index at $7^{\text {th }}$ day post infection were calculated at $7^{\text {th }}$ day post-infection (Fig. 4).

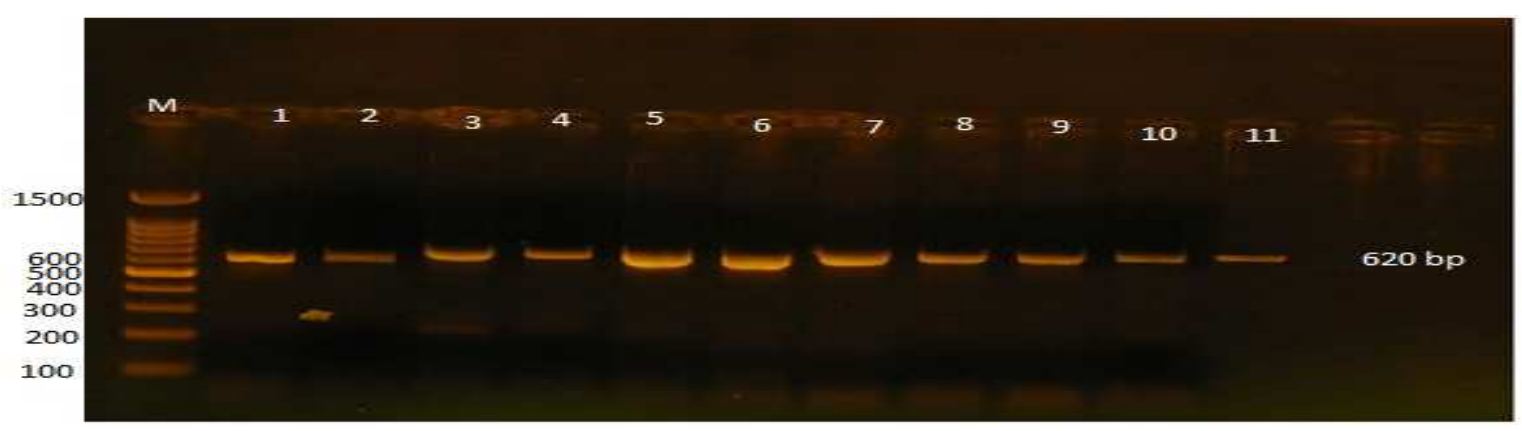

Fig. 1: Gel electrophoresis of RT-PCR showing $620 \mathrm{bp}$ bands in11 positive field isolates

\begin{tabular}{|c|c|c|c|c|c|c|c|c|c|c|c|c|c|c|c|c|c|c|c|}
\hline \multicolumn{20}{|c|}{ Percent Identity } \\
\hline & 1 & 2 & 3 & 4 & 5 & 6 & 7 & 8 & 9 & 10 & 11 & 12 & 13 & 14 & 15 & 16 & 17 & & \\
\hline 1 & & 91.2 & 91.9 & 94.4 & 92.5 & 90.6 & 85.0 & 96.9 & 80.6 & 97.5 & 85.6 & 85.0 & 94.4 & 90.0 & 96.9 & 96.9 & 96.9 & 1 & Giza 2008 \\
\hline 2 & 9.3 & & 94.4 & 95.6 & 95.0 & 91.9 & 83.8 & 91.9 & 75.6 & 92.5 & 80.0 & 79.4 & 89.4 & 84.4 & 88.8 & 91.9 & 91.9 & 2 & D78 VA \\
\hline 3 & 8.6 & 5.9 & & 97.5 & 99.4 & 92.5 & 84.4 & 92.5 & 76.2 & 93.1 & 80.6 & 80.0 & 90.0 & 85.0 & 89.4 & 92.5 & 92.5 & 3 & BursaVac \\
\hline 4 & 5.9 & 4.5 & 2.5 & & 98.1 & 93.8 & 86.9 & 95.0 & 78.8 & 95.6 & 83.1 & 82.5 & 92.5 & 87.5 & 91.9 & 95.0 & 95.0 & 4 & CEVAC IBD L \\
\hline 5 & 7.9 & 5.2 & 0.6 & 1.9 & & 93.1 & 85.0 & 93.1 & 76.9 & 93.8 & 81.2 & 80.6 & 90.6 & 85.6 & 90.0 & 93.1 & 93.1 & 5 & Univax \\
\hline 6 & 10.0 & 8.6 & 7.9 & 6.5 & 7.2 & & 81.2 & 91.2 & 74.4 & 91.9 & 79.4 & 78.8 & 88.8 & 83.8 & 88.1 & 91.2 & 91.2 & 6 & Bursine PLUS \\
\hline 7 & 16.8 & 18.4 & 17.6 & 14.5 & 16.8 & 21.6 & & 86.2 & 73.8 & 85.6 & 76.9 & 76.2 & 84.4 & 81.9 & 83.8 & 85.6 & 85.6 & 7 & IBD-F232-2-2015 \\
\hline 8 & 3.2 & 8.6 & 7.9 & 5.2 & 7.2 & 9.3 & 15.2 & & 81.9 & 98.1 & 86.9 & 86.2 & 95.0 & 90.0 & 94.4 & 97.5 & 97.5 & 8 & IBD-F232-4-2015 \\
\hline 9 & 22.5 & 29.5 & 28.6 & 25.0 & 27.7 & 31.4 & 32.3 & 20.8 & & 82.5 & 95.0 & 95.6 & 80.6 & 79.4 & 78.8 & 80.6 & 80.6 & 9 & IBD-F232-10-2015 \\
\hline 10 & 2.5 & 7.9 & 7.2 & 4.5 & 6.5 & 8.6 & 16.0 & 1.9 & 20.0 & & 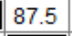 & 86.9 & 96.9 & 91.2 & 95.0 & 98.1 & 98.1 & 10 & IBD-F232-11-2015 \\
\hline 11 & 16.0 & 23.3 & 22.5 & 19.2 & 21.6 & 24.2 & 27.7 & 14.5 & 5.2 & 13.7 & & 99.4 & 84.4 & 83.8 & 83.8 & 85.6 & 85.6 & 11 & IBD-F232-16-2015 \\
\hline 12 & 16.8 & 24.2 & 23.3 & 20.0 & 22.5 & 25.0 & 28.6 & 15.2 & 4.5 & 14.5 & 0.6 & & 84.4 & 83.1 & 83.1 & 85.0 & 85.0 & 12 & IBD-F232-21-2016 \\
\hline 13 & 5.9 & 11.5 & 10.8 & 7.9 & 10.0 & 12.2 & 17.6 & 5.2 & 22.5 & 3.2 & 17.6 & 17.6 & & 88.8 & 91.9 & 95.0 & 95.0 & 13 & IBD-F232-22-2016 \\
\hline 14 & 10.8 & 17.6 & 16.8 & 13.7 & 16.0 & 18.4 & 20.8 & 10.8 & 24.2 & 9.3 & 18.4 & 19.2 & 12.2 & & 90.0 & 91.9 & 91.9 & 14 & IBD-F232-23-2016 \\
\hline 15 & 3.2 & 12.2 & 11.5 & 8.6 & 10.8 & 13.0 & 18.4 & 5.9 & 25.0 & 5.2 & 18.4 & 19.2 & 8.6 & 10.8 & & 95.0 & 95.0 & 15 & IBD-F232-24-2016 \\
\hline 16 & 3.2 & 8.6 & 7.9 & 5.2 & 7.2 & 9.3 & 16.0 & 2.5 & 22.5 & 1.9 & 16.0 & 16.8 & 5.2 & 8.6 & 5.2 & & 100.0 & 16 & IBD-F232-25-2016 \\
\hline 17 & 3.2 & 8.6 & 7.9 & 5.2 & 7.2 & 9.3 & 16.0 & 2.5 & 22.5 & 1.9 & 16.0 & 16.8 & 5.2 & 8.6 & 5.2 & 0.0 & & 17 & IBD-F232-26-2016 \\
\hline & 1 & 2 & 3 & 4 & 5 & 6 & 7 & 8 & 9 & 10 & 11 & 12 & 13 & 14 & 15 & 16 & 17 & & \\
\hline
\end{tabular}

Fig. 2: Nucleotide similarity percentage of 11 IBDV isolates with related strains in Gene Bank 


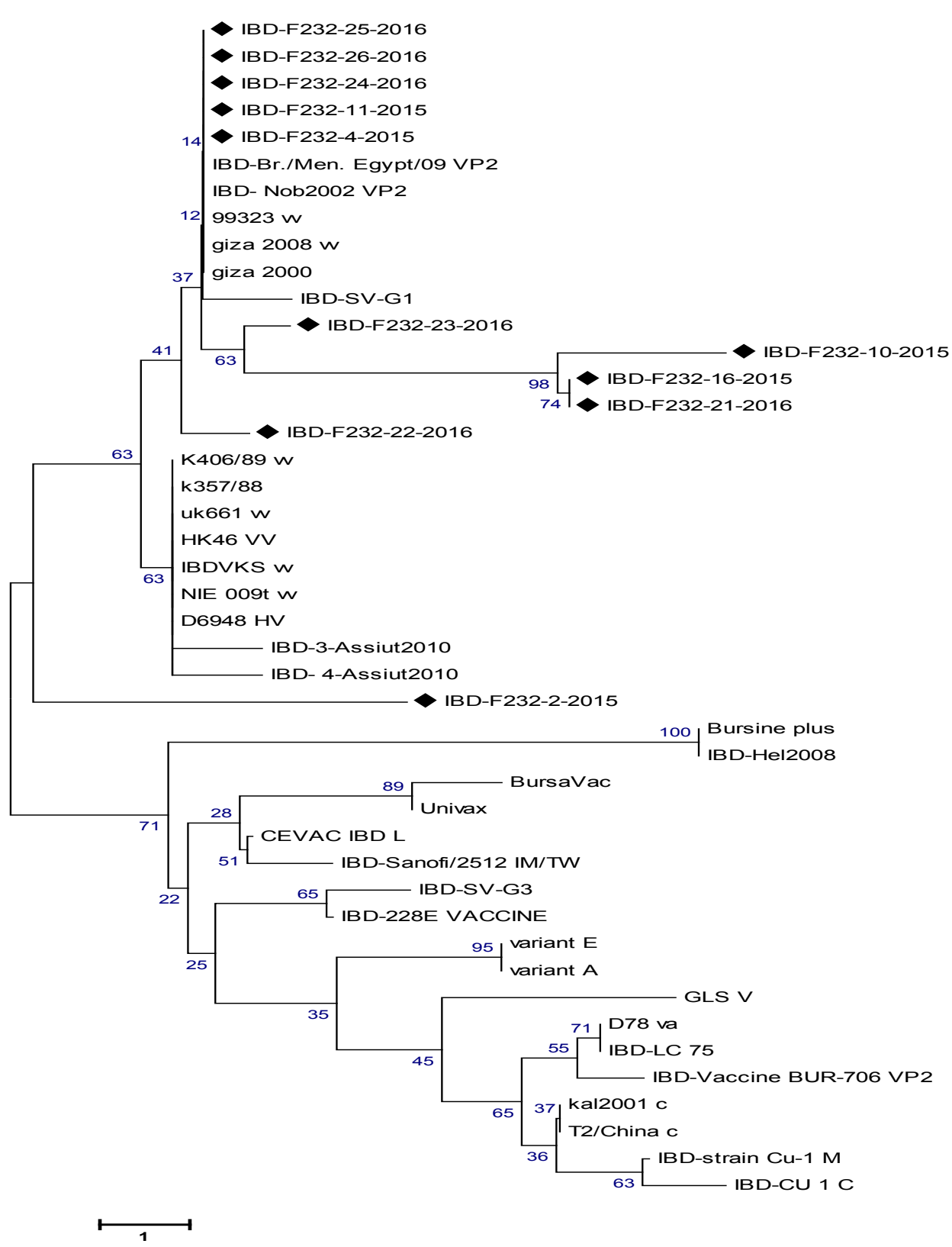

Fig. 3: Nucleotide Phylogenic tree of deduced amino acid sequences of the eleven IBDV field isolates and other reference classical, very virulent and variant and vaccine strains of IBDV

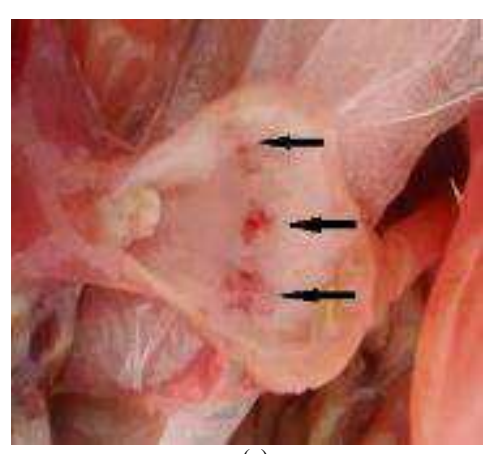

(a)

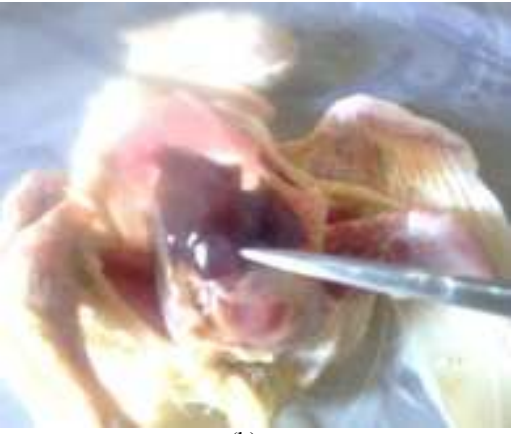

(b) 


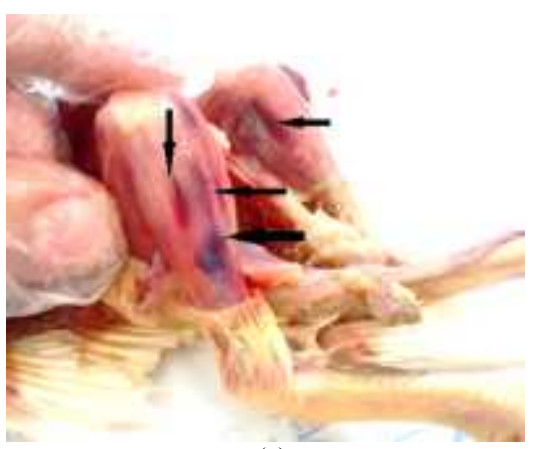

(c)

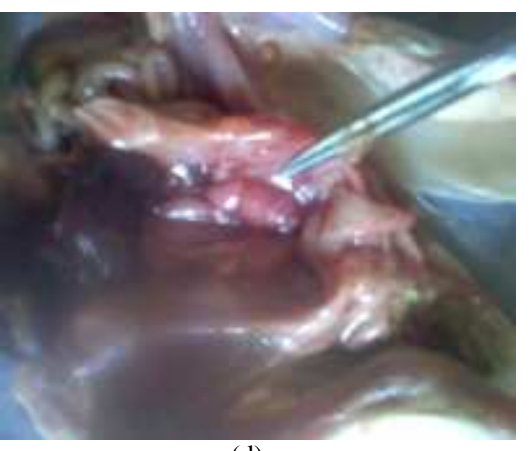

(d)

Fig. 4: Pathological lesions associated with IBDV infections: (a) showing hemorrhage in the Junction between proventriculus and gizzard; (b) Congested live; (c) showing hemorrhage on thigh muscles; (d) Swollen kidney and ureters filled with urates

Table 3: Experimental design of SPF chickens experimentally infected with Selected 6 IBDV field isolates

\begin{tabular}{|c|c|c|c|}
\hline Isolate no. & Type of birds & Governorate & RT-PCR \\
\hline 1 & Broilers & Behera & -ve \\
\hline 2 & Layers & Alex & $+\mathrm{ve}$ \\
\hline 3 & Broilers & Behera & $-\mathrm{ve}$ \\
\hline 4 & Layers & KFS & $+\mathrm{ve}$ \\
\hline 5 & Baladi & KFS & -ve \\
\hline 6 & Baladi & Behera & -ve \\
\hline 7 & Broilers & Alex & -ve \\
\hline 8 & Broilers & Alex & -ve \\
\hline 9 & Broilers & Alex & -ve \\
\hline 10 & Broilers & KFS & $+\mathrm{ve}$ \\
\hline 11 & Baladi & KFS & $+\mathrm{ve}$ \\
\hline 12 & Layers & Alex & -ve \\
\hline 13 & Broilers & Behera & -ve \\
\hline 14 & Baladi & KFS & -ve \\
\hline 15 & Layers & KFS & -ve \\
\hline 16 & Baladi & Alex & $+\mathrm{ve}$ \\
\hline 17 & Broilers & Behera & $-\mathrm{ve}$ \\
\hline 18 & Broilers & Behera & -ve \\
\hline 19 & Layers & KFS & -ve \\
\hline 20 & Broilers & Behera & -ve \\
\hline 21 & Broilers & Behera & $+\mathrm{ve}$ \\
\hline 22 & Broilers & Matrouh & $+\mathrm{ve}$ \\
\hline 23 & Broilers & Behera & $+\mathrm{ve}$ \\
\hline 24 & Broilers & Behera & $+\mathrm{ve}$ \\
\hline 25 & Baladi & Behera & $+\mathrm{ve}$ \\
\hline 26 & Baladi & Behera & $+\mathrm{ve}$ \\
\hline
\end{tabular}

G: Group No: Number -ve: Negative EID50 = Embryo Infective Dose 50

Table 4: Experimental design of SPF chickens experimentally infected with Selected 6 IBDV field isolates

\begin{tabular}{|c|c|c|c|c|c|c|c|c|c|c|}
\hline \multirow[b]{2}{*}{ Group } & \multirow[b]{2}{*}{ Field isolate } & \multirow[b]{2}{*}{ No. of birds } & \multicolumn{6}{|c|}{ Mortality at days of observation } & \multicolumn{2}{|c|}{ Total mortality } \\
\hline & & & $1 \mathrm{st}$ & 2nd & $3 \mathrm{rd}$ & 4th & 5 th & 6th & Number & $\%$ \\
\hline 1 & 21 & 15 & 0 & 0 & 1 & 2 & 1 & 1 & 5 & 33.3 \\
\hline 2 & 22 & 15 & 0 & 0 & 3 & 4 & 1 & 1 & 9 & 60.0 \\
\hline 3 & 23 & 15 & 0 & 0 & 4 & 5 & 3 & 0 & 12 & 80.0 \\
\hline 4 & 24 & 15 & 0 & 0 & 2 & 3 & 1 & 1 & 7 & 46.7 \\
\hline $\mathrm{z} 5$ & 25 & 15 & 0 & 0 & 2 & 3 & 1 & 0 & 6 & 40.0 \\
\hline 6 & 26 & 15 & 0 & 0 & 0 & 1 & 2 & 1 & 4 & 26.7 \\
\hline 7 & Control - & 15 & 0 & 0 & 0 & 0 & 0 & 0 & 0 & 0.0 \\
\hline
\end{tabular}


Table 5: Average of bursa/body weight ratio and bursa/body weight index

\begin{tabular}{lllll}
\hline Group & $\begin{array}{l}\text { Average body } \\
\text { weight in grams }\end{array}$ & $\begin{array}{l}\text { Average bursal } \\
\text { weight in grams }\end{array}$ & $*$ average B/BW ratio & $* * \mathrm{~B} / \mathrm{BW}$ ratio 7 \\
1 & 95.2 & 0.16 & 1.66 & 0.32 \\
2 & 85.7 & 0.20 & 2.37 & 0.45 \\
3 & 105.3 & 0.16 & 1.52 & 0.29 \\
4 & 100.5 & 0.10 & 1.07 & 0.20 \\
5 & 93.7 & 0.16 & 1.70 & 0.32 \\
6 & 112.8 & 0.15 & 1.30 & 0.25 \\
7 & 100.2 & 0.52 & 5.22 & 1.00 \\
\hline
\end{tabular}

\section{The Average Bursa and Body Weight Index}

The calculated average bursa weight to bird body weight and detected ration showed in Table 5. The calculated bursa and body weight index in dead and scarified birds at the 7th day post infection showed in Table 5.

\section{Histopathological Examination}

The histopathological Bursal changes in infected groups at 3rd and 7th days post infected were shown in Fig. 5.

\section{Discussion}

HI In the current study, Virus isolation of bursal suspension in SPF embryonated chicken eggs was carried out to confirm the presence of the etiological and the picture in embryonated chicken eggs matched with the IBD lesions. The embryo mortalities were varied between $0-100 \%$, dead embryos showed typical IBDV gross lesions; These embryonic changes were in agreement with Rosenberger et al. (1998). The histopathological Bursal changes in infected groups at $3^{\text {rd }}$ and $7^{\text {th }}$ days post infected were matches with IBD typical lesions where The bursa of Fabricius of chickens in group-1 during $3^{\text {rd }}$ day showing lymphoid depletion, subepithelium edema (A), atrophy of the follicles (stars) and presence of cystic cavity formation of follicles as shown in Fig. 5a. The bursa of Fabricius of chickens in group-2 during $3^{\text {rd }}$ day showing lymphoid depletion with proliferating interfollicular connective tissue (A) and desquamation of bursal epithelium (stars) as shown in Fig. 5b. The bursa of Fabricius of chickens in group-3 during $3^{\text {rd }}$ day showing lymphoid depletion, atrophy of the follicles, stromal edema (A) and associated with inflammatory response (stars) as shown in Fig. 5c. The bursa of Fabricius of chickens in group- 4 during $3^{\text {rd }}$ day showing lymphoid depletion with proliferating interfollicular connective tissue and sub epithelium edema as shown in Fig. 5d. The bursa of Fabricius of chicken in group-5 of during $3^{\text {rd }}$ day showing the most of follicles medulla replaced with eosinophilic material (stars) as shown in Fig. 5e. The bursa of Fabricius of chicken in group-6 during $3^{\text {rd }}$ day showing mild lymphoid depletion and widening of medulla (M) at the expanse of cortex as shown in Fig. 5f. The bursa of Fabricius of chicken in the control negative group during $3^{\text {rd }}$ day showing normal histological structure of cortex (C) and medulla (M) as shown in Fig. 5g. The bursa of Fabricius of chicken group-1 during $7^{\text {th }}$ day showing lymphoid depletion and necrosis of the follicles (stars) as shown in Fig. 5h. The bursa of Fabricius of chicken in group- 2 during $7^{\text {th }}$ day showing lymphoid depletion with proliferating interfollicular connective tissue; beside inflammatory cell infiltrations (A) as shown in Fig. 5k. The bursa of Fabricius of chicken in group-3 during $7^{\text {th }}$ day showing lymphoid depletion, atrophy of the follicles, stromal edema and fibrosis (A) and associated with inflammatory response with presence of cystic cavity formation of follicles as shown in Fig. $5 \mathrm{~m}$. The bursa of Fabricius of chicken in group- 4 during $7^{\text {th }}$ day showing lymphoid depletion with proliferating interfollicular connective tissue beside inflammatory cell infiltrations as shown in Fig. 5n. The bursa of Fabricius of chicken in group-5 during $7^{\text {th }}$ day showing lymphoid depletion, sub-epithelium edema (A) and atrophy of the follicles as shown in Fig. 5o. The bursa of Fabricius of chicken in group-6 during $7^{\text {th }}$ day showing lymphoid depletion with proliferating interfollicular connective tissue as shown in Fig. 5p. The bursa of Fabricius of a chicken of the control negative group during $7^{\text {th }}$ day showing normal histological structure of cortex (C) and medulla (M) as shown in Fig 5q. The RT-PCR consider a useful and sensitive test in detecting IBDV serotypes, in the present study, RT-PCR was used to amplify a $620 \mathrm{bp}$ fragment length within IBDV on VP2 gene from bursal samples and found that 11 out of 26 field isolates were positive by RT-PCR with a percent of $42.3 \%$; which confirmed the embryonated chicken egg isolation steps and the obtained results from this step matched with Similar study was carried by Mawgod et al. (2014). In this study, a comparative alignment and phylogenetic analysis of the hypervariable domain of the VP2 revealed that all isolates were highly genetically related, have amino acid identity between each other (73.8-100\%) and between Egyptian vvIBDV (Giza 2008) strain (80.6-97.5\%) identity but when compared with classical vaccinal strains it showed (74.4-95.6\%) identity. This amino acid substitution may affect virus antigenicity change which may has an important role in increasing virulence that may cause disease in the presence of high maternal antibody. In this study, all isolates show the same amino acids at position 222 A, 242I, 253 G, 256 I, 279D, 284 A, 
294 I, 299S and $330 \mathrm{~S}$ except $451 \mathrm{~L}$ not involved in the sequenced fragment in this study this findings agreed with Jackwood et al. (2008) Residues present in the VP2 region at position (P222A), (V242I), (G253Q), (V256I), (N279D), (T284 A), (L294I) and (N299S, (R330S) and $451(\mathrm{~L}))$ reported to be unique for all vvIBDV strains as compared to classical strains (Van den Berg et al., 2004). Strains that have glutamine at position 253 reported to be high pathogenicity than those with a histidine at position 253 were much less pathogenic. A glutamine residue at position 253 was found in the eleven isolates examined in our study as well as the previously isolated Giza 2008, Giza 2000 IBDV indicating high pathogenicity. These results agreed with Brandt et al. (2001) who reported that reverse genetic experiments have shown that the amino acid at position 253in VP2 affects the virulence of IBDV.

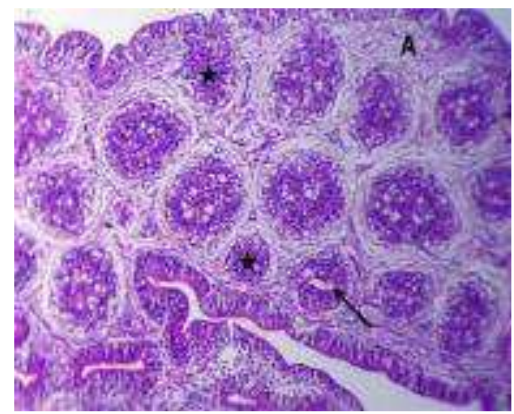

(a)

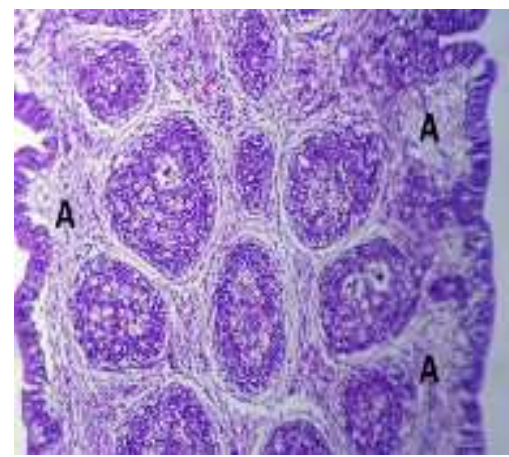

(d)

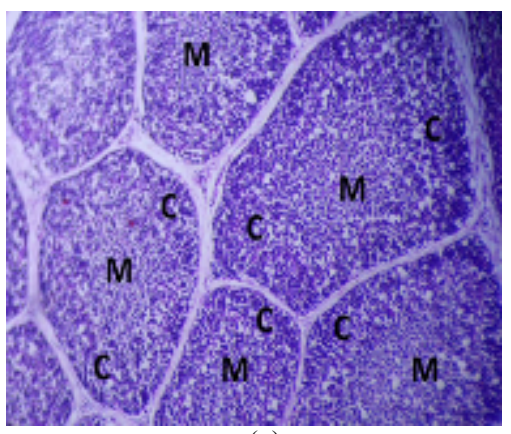

(g)

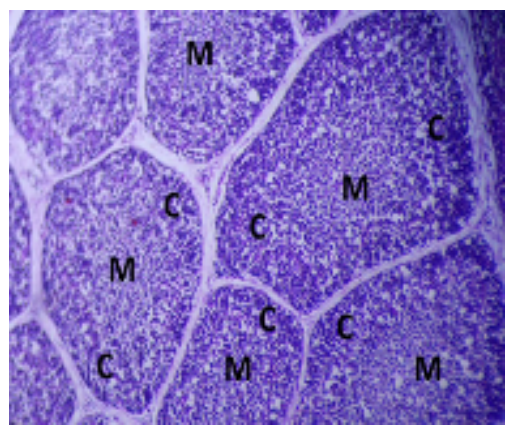

(j)

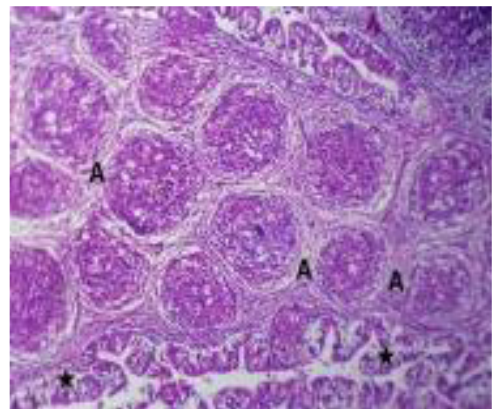

(b)

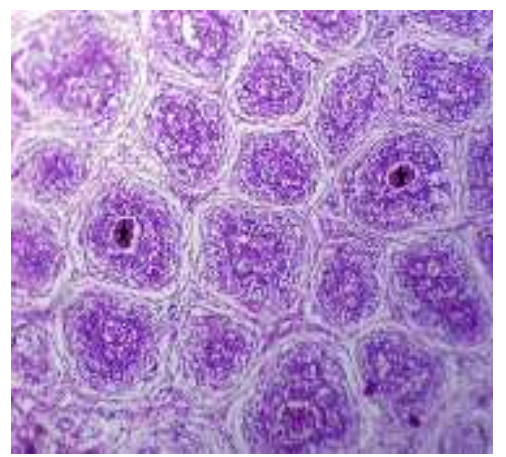

(e)

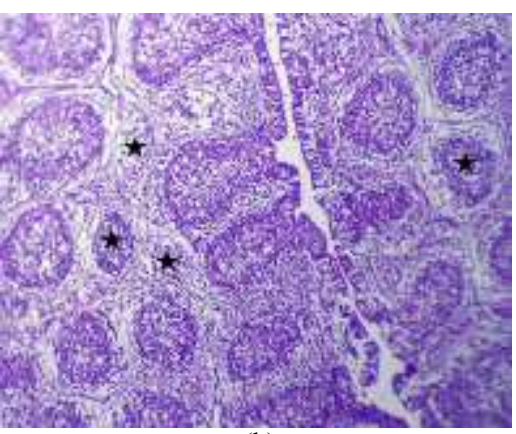

(h)

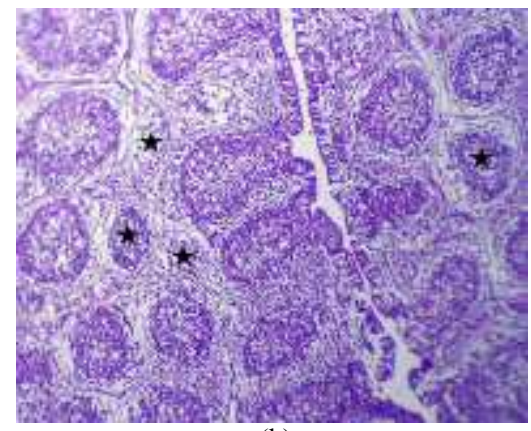

(k)

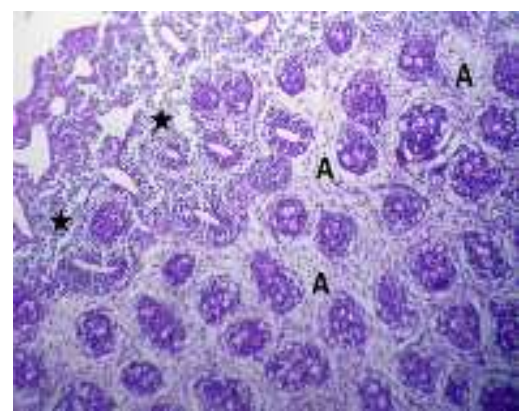

(c)

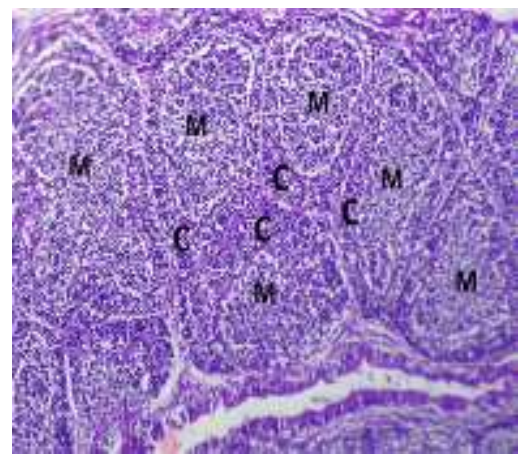

(f)

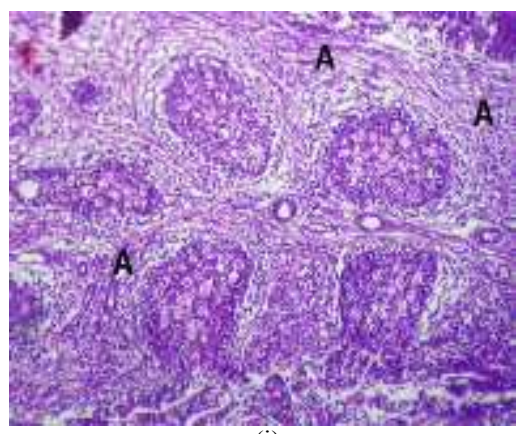

(i)

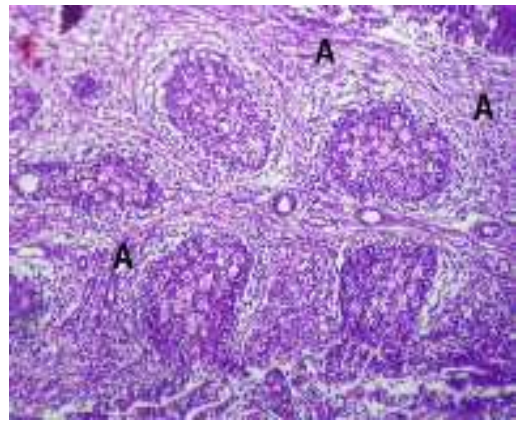

(1) 


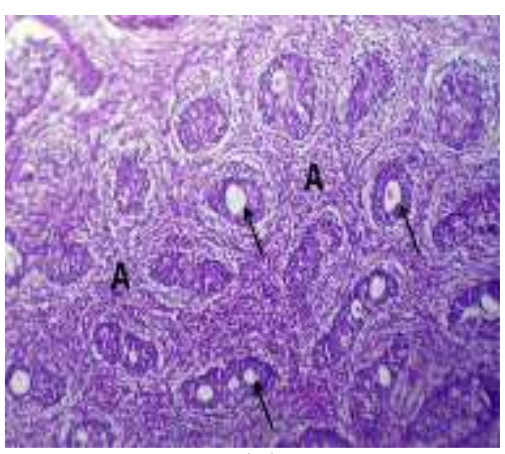

$(\mathrm{m})$

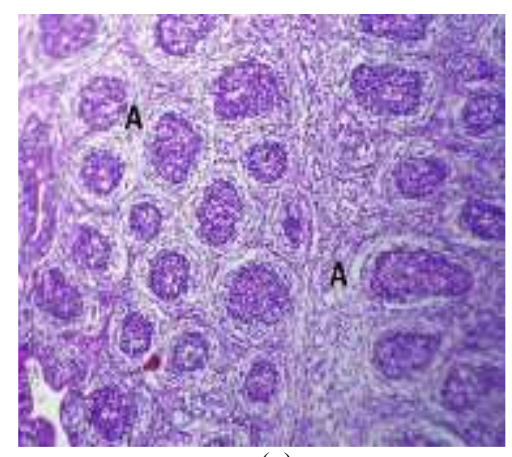

(n)

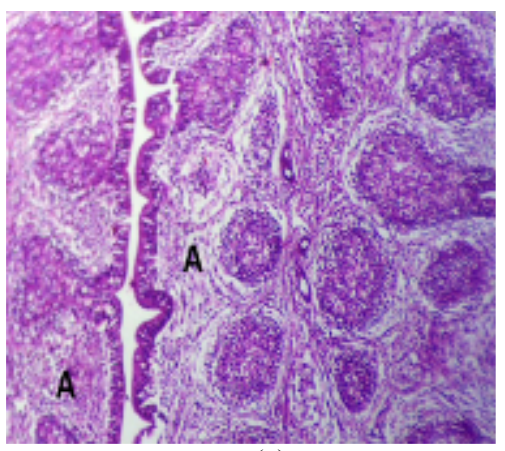

(o)

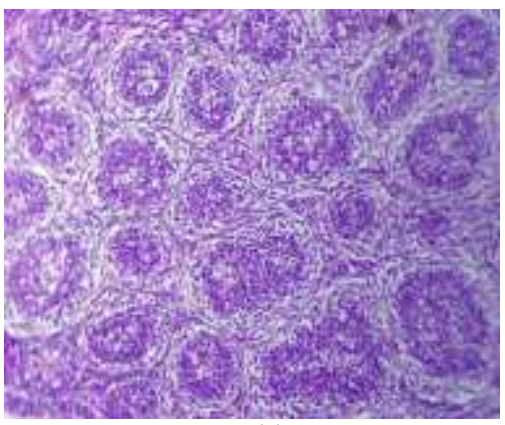

(p)

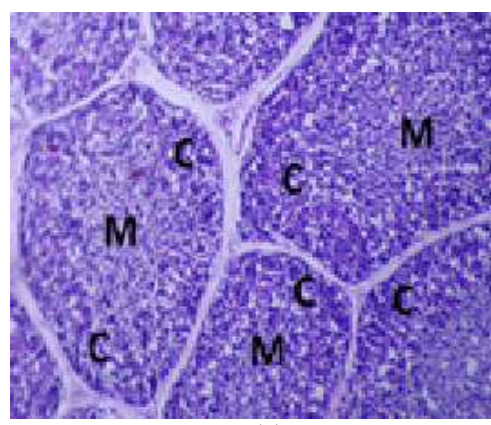

(q)

Fig. 5: Histopathological Bursal changes in infected groups at 3rd and 7th days post infected: (a): The bursa of Fabricius of a chicken of the Gr 1 during $3^{\text {rd }}$ day showing lymphoid depletion, sub-epithelium edema (A),atrophy of the follicles (stars) and presence of cystic cavity formation of follicles, (arrow). H\&E. (X200). (b): The bursa of Fabricius of a chicken of the Gr 2 during 3rd day showing lymphoid depletion with proliferating interfollicular connective tissue (A) and desquamation of bursal epithelium (stars). H\&E. (X200). (c): The bursa of Fabricius of a chicken of the Gr 3 during 3rd day showing lymphoid depletion, atrophy of the follicles, stromal edema (A) and associated with inflammatory response (stars). H\&E. (X200). (d): The bursa of Fabricius of a chicken of the Gr 4 during 3rd day showing lymphoid depletion with proliferating interfollicular connective tissue and sub epithelium edema (A). H\&E. (X200). (e): The bursa of Fabricius of a chicken of the Gr 5 during 3rd day showing the most of follicles medulla replaced with eosinophilic material (stars). H\&E. (X200). (f): The bursa of Fabricius of a chicken of the Gr 6 during 3rd day showing mild lymphoid depletion and widening of medulla (M) at the expanse of cortex (C). H\&E. (X200).(g): The bursa of Fabricius of a chicken of the control negative during 3rd day showing normal histological structure of cortex (C) and medulla (M). H\&E. (X200). (k): The bursa of Fabricius of a chicken of the Gr1 during 7th day showing lymphoid depletion and necrosis of the follicles (stars). H\&E. (X200). (I): The bursa of Fabricius of a chicken of the Gr 2 during 7th day showing lymphoid depletion with proliferating interfollicular connective tissue H\&E. (X200). Beside inflammatory cell infiltrations (A) H\&E. (X160). (m): The bursa of Fabricius of a chicken of the Gr 3 during 7th day showing lymphoid depletion, atrophy of the follicles, stromal edema and fibrosis (A) and associated with inflammatory response, with presence of cystic cavity formation of follicles, (arrows). (H\&E. (X200). (n): The bursa of Fabricius of a chicken of the Gr 4 during 7th day showing lymphoid depletion with proliferating interfollicular connective tissue beside inflammatory cell infiltrations (A). H\&E. (X160). (o): The bursa of Fabricius of a chicken of the Gr 5 during 7th day showing lymphoid depletion, sub-epithelium edema (A) and atrophy of the follicles. H\&E. (X200). (p): The bursa of Fabricius of a chicken of the Gr 6 during 7th day showing lymphoid depletion with proliferating interfollicular connective tissue. (q): The bursa of Fabricius of a chicken of the control negative during 7th day showing normal histological structure of cortex (C) and medulla (M). H\&E. (X200)

The serine rich heptapeptide SWSASGS (326-332) located immediately downstream of the second hydrophilic region was believed to be involved in the virulence of IBDV (Heine et al., 1991). At this study presence of typical heptapeptide (SWSASGS) in the eleven examined samples indicating that they were pathogenic strains. This was in agreement with Heine et al. (1991). The presence of the specific SspI restriction site on VP2 corresponds to the substitution at residue (leucine L 294I isoleucine) was previously reported to be characteristic of vvIBDV strains (Jackwood et al., 2008). All vvIBDV isolates under study had this restriction site while it was not observed in vaccine (classic) strain. Results of this study agreed with Mawgod et al. (2014). The results of this study, speculate that, the isolated strains are highly related to vvIBDV strains belonging to serotype-1 isolates and indicating that they were pathogenic strains and that vvIBDV belong to Egyptian 
strains succeeded in surviving in the Egyptian environment despite the intensive use of vaccination programs. This observation agreed with Mawgod et al. (2014). The titre of six characterized IBDV field isolates ranged from $10^{-3.5}$ to $10^{-4.8} \mathrm{EID}_{50} / 0.1 \mathrm{~mL}$ homogenate and the infective dose per isolate used in pathogenicity test was $0.1 \mathrm{ml} \mathrm{EID}$ 50 $/$ bird (Sultan et al., 2012). Experimentally infected chickens induced $80-100 \%$ morbidity. The mortality rate varied from 26.7 up to $80 \%$, suggested that all isolates were probably of the vvIBDV pathotype. Presence of vvIBDV strains in Egyptian environment were reported also by Metwally et al. (2009). The bursa /body weight index of all infected groups in comparison with non-infected control showed different degrees of bursal atrophy $(<0.7)$. Bursal atrophy 7 days post infection was supported by Hussein (2006), who mentioned that bursal atrophy began at 5-8 days post infection. In this study, the histopathological findings were characteristic to vvIBDV infection. All isolates induced bursal lesions, which began at $3^{\text {rd }}$ day post infection and continued to day 7 post-infection. The lesions were severe in groups $-2,-3$ and -4 ; moderate in groups -1 and -5 and mild in group- 6 . The bursae of fabricius of control negative group showing normal histological structure.The results of this study were in agreement with the results obtained by Jackwood et al. (2011).

\section{Conclusion}

The present study concluded that the circulating strains were highly related to vvIBDV strains belonging to serotype-1 isolates and indicating that they are highly pathogenic to 21-day-old SPF chickens and that vvIBDV strains succeeded in surviving in the Egyptian farms despite of the application of intensive vaccination programs.

\section{Acknowledgement}

Author acknowledge the support from Alexandria University

\section{Conflicts of Interest}

All authors have no conflict of interest.

\section{Author's Contributions}

Ashraf M. Awad, Mahmoud E Sedeik and Wael

K. Elfeil: Conceived and designed the experiments.

Heba Rashed and Mahmoud E Sedeik: Performed the experiments.

Ashraf M. Awad, Mahmoud E Sedeik and Wael

K. Elfeil: Analyzed the data.

Ashraf M. Awad, Mahmoud E Sedeik and Heba

Rashed: Contributed reagents/materials/analysis tools.
Ashraf M. Awad, Mahmoud E Sedeik and Wael K. Elfeil: Wrote the paper.

\section{Ethics}

The experiment approved by Alexandria University ethical committee.

\section{References}

Abouelmaatti, R.R., A.M. Algammal, X. Li, J. Ma and E.A. Abdelnaby et al., 2013. Experimental immunology Cloning and analysis of Nile tilapia Toll-like receptors type-3 mRNA. Central Eur. J. Immunol., 38: 277-282.

DOI: $10.5114 /$ ceji.2013.37740

Brandt, M., K. Yao, M. Liu, R.A. Heckert and V.N. Vakharia, 2001. Molecular determinants of virulence, cell tropism and pathogenic phenotype of infectious bursal disease virus. J. Virol., 75: 11974-11982. DOI: 10.1128/JVI.75.24.11974-11982.2001

Cosgrove, A., 1962. An apparently new disease of chickens: Avian nephrosis. Avian Dis., 6: 385-389. DOI: $10.2307 / 1587909$

Culling, C.F.A., 1974. Handbook of Histopathological and Histochemical Techniques: (Including Museum Techniques). 1st Edn., Butterworths, London, ISBN-10: 0407729011, pp: 712.

Eid, H.I., A.M. Algammal, S.A. Nasef, W.K. Elfeil and G.H. Mansour, 2016. Genetic variation among avian pathogenic E. coli strains isolated from broiler chickens. Asian J. Anim. Vet. Adv., 11: 350-356. DOI: 10.3923/ajava.2016.350.356

El-Batrawi, A., 1990. Studies on sever outbreaks of infectious bursal disease 3-deternination of the critiealage of sysceptigilty in maternally immune chicks. Proceedings of the 2nd Science Conference Egypt Vet Poult, (EVP' 90), pp: 264-269.

El-Sergany, M., A. Moursi, M. Saber and M. Mohamed, 1974. A preliminary investigation on the occurrence of Gumboro disease in Egypt [chickens]. Egypt. J. Vet. Sci. (Egypt).

Elfeil, W.K., R.R. Abouelmaatti, C. Sun, W. Han and X. Li et al., 2012. Identification, cloning, expression of a novel functional Anas platyrhynchos mRNA TLR4. J. Anim. Vet. Adv., 11: 1727-1733. DOI: $10.3923 /$ javaa.2012.1727.1733

Elfeil, W.M.K., A.M. Algammal, R.R. Abouelmaatti, A.R. Gardouh and M.M. Abdel-Daim, 2016. Molecular characterization and analysis of TLR-1 in rabbit tissues. Central Eur. J. Immunol., 41: 236-242. DOI: $10.5114 /$ ceji.2016.63121

Eterradossi, N. and Y.M. Saif, 2013. Infectious Bursal Disease. In: Diseases of Poultry, Suarez, D.L., J.R. Glisson, L.R. McDougald, L.K. Nolan and V. Nair (Eds.), Wiley- Blackwell, pp: 219-246. 
Heine, H.G., M. Haritou, P. Failla, K. Fahey and A. Azad, 1991. Sequence analysis and expression of the host-protective immunogen VP2 of a variant strain of infectious bursal disease virus which can circumvent vaccination with standard type I strains. J. General Virol., 72: 1835-1843.

DOI: $10.1099 / 0022-1317-72-8-1835$

Hirai, K. and S. Shimakura, 1974. Structure of infectious bursal disease virus. J. Virol., 14: 957-964.

Hussein, E.G.S., 2006. Further studies on infectious bursal disease virus in growing chickens. Alexandria University, Alexandria University.

Islam, M., S. Rahman, M. Noor, E. Chowdhury and H. Müller, 2012. Differentiation of Infectious Bursal Disease Virus (IBDV) genome segment B of very virulent and classical lineage by RT-PCR amplification and restriction enzyme analysis. Arch Virol., 157: 333-336. DOI: 10.1007/s00705-011-1159-9

Jackwood, D., B. Sreedevi, L. LeFever and S. SommerWagner, 2008. Studies on naturally occurring infectious bursal disease viruses suggest that a single amino acid substitution at position 253 in VP2 increases pathogenicity. Virology, 377: 110-116.

DOI: 10.1016/j.virol.2008.04.018

Jackwood, D.J., S.E. Sommer-Wagner, B.M. Crossley, S.T. Stoute and P.R. Woolcock et al., 2011. Identification and pathogenicity of a natural reassortant between a very virulent serotype 1 Infectious Bursal Disease Virus (IBDV) and a serotype 2 IBDV. Virology, 420: 98-105.

DOI: $10.1016 /$ j.virol.2011.08.023

Leong, J., D. Brown, P. Dobos, F. Kibenge and J. Ludert et al., 2000. Family birnaviridae. Virus taxonomy: Classification and nomenclature of viruses. Seventh Report of the International Committee on Taxonomy of Viruses.

Lucio, B. and S.B. Hitchner, 1979. Infectious bursal disease emulsified vaccine: Effect upon neutralizing-antibody levels in the dam and subsequent protection of the progeny. Avian Dis., 466-478. DOI: $10.2307 / 1589577$

Mawgod, S.A., A.S. Arafa and H.A. Hussein, 2014. Molecular genotyping of the Infectious Bursal Disease Virus (IBDV) isolated from Broiler Flocks in Egypt. Int. J. Vet. Sci. Med., 2: 46-52.

DOI: $10.1016 /$ j.ijvsm.2014.02.004
McFerran, J., M. McNulty, E. McKillop, T. Connor and R. McCracken et al., 1980. Isolation and serological studies with infectious bursal disease viruses from fowl, turkeys and ducks: Demonstration of a second serotype. Avian Pathol., 9: 395-404. DOI: $10.1080 / 03079458008418423$

Metwally, A.M., A.A. Yousif, I.B. Shaheed, W.A. Mohammed and A.M. Samy et al., 2009. Reemergence of very virulent IBDV in Egypt. Int. J. Virol., 5: 1-17. DOI: 10.3923/ijv.2009.1.17

Müller, H., M.R. Islam and R. Raue, 2003. Research on infectious bursal disease-the past, the present and the future. Vet. Microbiol., 97: 153-165. DOI: $10.1016 /$ j.vetmic. 2003.08 .005

Parkhurst, R.T., 1964. Pattern of Mortality in Avian Nephrosis. Poult. Sci., 43: 788-790. DOI: $10.3382 /$ ps.0430788

Reed, L.J. and H. Muench, 1938. A simple method of estimating fifty percent endpoints. Am J Hygiene.

Rosenberger, J.K., Y.M. Saif and D.J. Jackwood, 1998. Infectious Bursal Disease. In: A Laboratory Manual for the Isolation and Identification of Avian Pathogens, Swayne, D.E., J.R. Glisson, M.W. Jackwood and W.M. Reed (Eds.), American Association of Avian Pathologists, USA, pp: 215-218.

Sultan, H., H.A. Hussein, A.G.A. El-Razik, S. El-Balall and S.M. Talaat and A.A. Shehata, 2012. Efficacy of HVT-IBDV vector vaccine against recent Egyptian vvIBDV in commercial broiler chickens. Int. J. Poultry Sci., 11: 710-710. DOI: 10.3923/ijps.2012.710.717

Van den Berg, T., D. Morales, N. Eterradossi, G. Rivallan and D. Toquin et al., 2004. Assessment of genetic, antigenic and pathotypic criteria for the characterization of IBDV strains. Avian Pathol., 33: 470-476. DOI: 10.1080/03079450400003650

Wlliams, S.M., 2016. A laboratory manual for the isolation, identification and characterization of avian pathogens. American Association of Avian Pathologists, Jacksonville, Fl. 